\title{
BIOgeografias Como Perspectiva Epistêmica das Artes Visuais Descoloniais Fronteiriças ${ }^{12}$
}

\author{
BIOgeografías Como Perspectiva Epistémica de las Artes Visuales \\ Descoloniales Fronterizas \\ BIOgeographies As an Epistemic Perspective of the Border Descolonial \\ Visual Arts
}

\author{
Prof. Dr. Marcos Antônio Bessa-Oliveira ${ }^{3}$
}

\begin{abstract}
Resumo
As produções no Brasil sempre passaram por tendências! Na arte, nas suas diferentes possibilidades, não é diferente! Na produção artística, na teoria e na crítica sobre a arte, e no ensino de Arte sempre estivemos ancorados em tendências vindas de lugares alheios às realidades brasileiras. Tendências sempre são passíveis de existência! Na arte, na cultura e no conhecimento sempre irão, dos e nos diversos lugares, haver tendências de pesquisas, práticas, mesmo no ensino de Arte que migram de lugares para lugares. Graças às memórias, histórias, experiências, sujeitos, espaços e narrativas particulares - Bio-sujeitos, geo-espaços, grafias-narrativas = Biogeografias -, teremos infinitas tendências na arte, na cultura e no conhecimento emergentes de tempos em tempos infinitamente. No século XXI a rapidez das tendências é cada vez maior! E no Brasil as tendências sempre encontram lugares aninhadores! O que mostra diferenças em relação à perspectiva histórica em e de vários lugares. Logo, cada paisagem biogeográfica precisa de uma espécie de tendência para ser compreendida no contexto onde emerge enquanto arte. A ideia deste trabalho é discutir, sem ser tendência, na arte, na cultura e nos conhecimentos, nas biogeografias de Mato Grosso do Sul-Brasil, os postulados teóricos e de teorias e artísticos emergentes contemporâneos ou os mantidos para pensar a arte, a cultura e os conhecimentos locais, desde a modernidade (séculos XV/XVI), ainda que MS só fosse criado quando dividido de Mato Grosso em 1977. Tomo das epistemologias culturais (Estudos de Culturas) consolidadas nos lugares emergentes latinos para pensar os fazeres artísticos. Pois, das produções teóricas e artísticas de lóci com paisagens biogeográficas outras é possível estabelecer reflexões teóricas e artísticas da arte, cultura e conhecimento de Mato Grosso do Sul, por exemplo, que não são tendências migrantes, mas são divergentes das paisagens clássicas e/ou modernas insistentes na cultura brasileira desde 1500 .
\end{abstract}

Palavras-Chave: Paisagem; Artes Visuais; Descolonização Fronteiriça; Biogeografias.

\footnotetext{
${ }^{1}$ Este trabalho está vinculado a um Projeto de Pesquisa maior cadastrado na PROPP/UEMS - Cadastro de ${ }^{\circ}$ 1271/2015 DP - intitulado "Arte e Cultura na Frontera: "Paisagens" Artísticas em Cena nas "Práticas Culturais" Sul-Mato-Grossenses". Uma primeira versão, sob o título: "BIOGEOGRAFIAS DESCOLONIAIS FRONTEIRIÇA: perspectiva teórica em Artes no século XXI", foi publicada nos Cadernos de Estudos Culturais: Tendências Teóricas do Século XXI, v. 9, n. 18 (2017) - disponível em: http://seer.ufms.br/index.php/cadec/article/view/5687.
}

2 Artigo apresentado no Simpósio Temático ST 05 - Fronteiras Culturais em Contextos Epistêmicos Descoloniais II durante o II Seminário Latino-Americano de Estudos em Cultura - SEMLACult em Foz do Iguaçu/PR, Brasil, 2018.

${ }^{3}$ Pós-Doutorando em Estudos de Linguagens - FAALC/UFMS, Doutor em Artes Visuais; Professor na UEMS Universidade Estadual de Mato Grosso do Sul, Coordenador do NAV(r)E - Núcleo de Artes Visuais em (re)Verificações Epistemológicas (CNPq/UEMS); Campo Grande, Mato Grosso do Sul - Brasil; marcosbessa2001@gmail.com. 


\begin{abstract}
Resumen
¡Las producciones en Brasil siempre pasaron por tendencias! En el arte, en sus diferentes posibilidades, no es diferente! En la producción artística, en la teoría y en la crítica sobre el arte, y en la enseñanza de Arte siempre estuvimos anclados en tendencias venidas de lugares ajenos a las realidades brasileñas. ¡Tendencias siempre son pasibles de existencia! En el arte, en la cultura y en el conocimiento siempre van, de los y en los diversos lugares, tener tendencias de investigaciones, prácticas, incluso en la enseñanza de Arte que emigran de lugares a lugares. Gracias a las memorias, historias, experiencias, sujetos, espacios y narrativas particulares - Bio-sujetos, geo-espacios, grafías-narrativas = Biogeografías - , tendremos infinitas tendencias en el arte, la cultura y el conocimiento emergentes de tiempos en tiempo infinitamente. En el siglo XXI la rapidez de las tendencias es cada vez mayor. Y en Brasil las tendencias siempre encuentran lugares anidadores! Lo que muestra diferencias en relación a la perspectiva histórica en y de varios lugares. Por lo tanto, cada paisaje biogeográfico necesita una especie de tendencia a ser comprendida en el contexto donde emerge como arte. La idea de este trabajo es discutir, sin ser tendencia, en el arte, en la cultura y los conocimientos, en las biogeografías de Mato Grosso del Sul-Brasil, los postulados teóricos y de teorías y artísticos emergentes contemporáneos o los mantenidos para pensar el arte, la cultura y los conocimientos locales, desde la modernidad (siglos XV/XVI), aunque MS sólo se creó cuando se dividía de Mato Grosso en 1977. Tomo de las epistemologías culturales (Estudios de Culturas) consolidadas en los lugares emergentes latinos para pensar los hechos artísticos. De las producciones teóricas y artísticas de lóci con paisajes biogeográficos otras es posible establecer reflexiones teóricas y artísticas del arte, cultura y conocimiento de Mato Grosso do Sul, por ejemplo, que no son tendencias migrantes, sino que son divergentes de los paisajes clásicos y/o modernos insistentes en la cultura brasileña desde 1500.
\end{abstract}

Palabras claves: Paisaje; Artes visuales; Descolonización Fronteriza; Biogeografias.

\begin{abstract}
The productions in Brazil have always been trending! In art, in its different possibilities, it is no different! In artistic production, in theory and in criticism of art, and in art teaching we have always been anchored in tendencies coming from places unrelated to Brazilian realities. Trends are always subject to existence! In art, in culture and in knowledge, there will always be, in and in different places, trends of research, practices, even in art teaching that migrate from places to places. Thanks to the particular memories, stories, experiences, subjects, spaces and narratives - Bio-subjects, geo-spaces, narrative-graffiti = Biogeographies - , we will have infinite tendencies in art, culture and knowledge emerging from time to time infinitely. In the 21 st century the speed of trends is increasing! And in Brazil trends always find nesting places! Which shows differences from the historical perspective in and from various places. Therefore, each biogeographic landscape needs a kind of tendency to be understood in the context where it emerges as an art. The idea of this work is to discuss, without being a tendency, in the art, culture and knowledge, in the biogeographies of Mato Grosso do Sul-Brazil, the theoretical postulates and emerging contemporary theories and artistic or those maintained to think the art, the culture and the local knowledge, from the modernity (centuries XV/XVI), although MS was only created when divided from Mato Grosso in 1977. Use of cultural epistemologies (Studies of Cultures) consolidated in the emerging Latin places to think the artistic actions. For from the theoretical and artistic productions of lóci with other biogeographic landscapes it is possible to establish theoretical and artistic reflections of art, culture and knowledge of Mato Grosso do Sul, for example, that are not migrant tendencies, but are divergent from the classical landscapes and / or insistent in Brazilian culture since 1500.
\end{abstract}

Keywords: Landscape; Visual arts; Border Decolonization; Biogeographies.

\title{
1. Introdução - tendências migram!
}

Quero dizer que as identidades culturais/biográficas dos sujeitos e os lugares geográficos desses sujeitos (artistas ou críticos) - as biogeografias - são pressupostos epistemológicos necessários para melhor contemplar e compreender as práticas artístico-culturais desses lugares e sujeitos marginalizados pelos discursos históricos hegemônicos (europeu ou estadunidense) que são distinguidos como subalternos. Especialmente porque desses lugares (a exemplo de Mato Grosso do Sul) as práticas artísticas e críticas ainda são objetos suscetíveis às produções dos centros hegemônicos. $(2018,91)$ 


\begin{abstract}
A primeira ideia que devemos ter em relação à pesquisa em arte está assentada na pluralidade de objetos, técnicas e sujeitos artísticos da atualidade. Por isso a noção primária deve ser "pesquisas em artes", no plural, quando se quer estabelecer alguns paradigmas para pensar os processos investigativos para a construção do que virá a ser desenvolvido como uma pesquisa em arte. Seja por quem for: artista, professor ou pesquisador. Portanto, "[...] a abertura da universidade para além de seus muros [...]" (SOUZA, 2011, p. 09) torna-se fundamental considerando a universidade como o único lugar da produção do saber intelectual disciplinar para convergir esses elementos da arte para o lugar da produção do conhecimento através da arte. (BARRETO; BESSA-OLIVEIRA, 2018, p. 37)
\end{abstract}

As práticas culturais de lugares colonizados têm, desde a imposição desses processos de colonização pelas diferentes coroas - portuguesa, inglesa, francesa ou espanhola -, características que as fazem ser "reconhecidas" como práticas que supostamente têm alguma relação com essas coroas que os colonizaram. Na América Latina, ao longo do último século (XX), vários teóricos, por exemplo, fizeram diferentes proposições da forma de "reconhecer" tais elementos das coroas que circunstanciam essas práticas culturais nas suas respectivas coroas colonizadoras. Do México, passando por Cuba, Colômbia, Brasil e até chegar ao Uruguai - de Néstor Canclini, Silvano Santiago, Fernández Retamar, à Hugo Achugar -, diferentes argumentações teóricas que já superavam as simples ideias de continuísmos das características culturais das coroas foram formuladas a partir do entendimento das práticas culturais latinas das suas próprias especificidades. Assim, igualmente as produções no Brasil que sempre passaram por tendências, na arte, nas suas diferentes possibilidades, não tiveram situação teórica muito diferente! Na produção artística, na teoria e na crítica sobre a arte, e até mesmo no ensino de Arte sempre estivemos ancorados em tendências (teóricas e/ou artísticas), vindas de lugares alheios às realidades brasileiras, até o surgimento de epistemes que nos tirassem desse lugar simplista de continuidade para a condição de propositores. Mas, de certa forma, a crítica brasileira, diferente da maioria dos críticos latinos, tomou e ainda tomam as teorias que migraram no século $\mathrm{XX}$ e as que migram no século $\mathrm{XXI}$ como tendências teóricas para pensar as práticas culturais nacionais insistindo na ideia de que nossas práticas são apenas tendências das práticas artístico-culturais daquelas coroas europeias. E tudo isso tem me sido uma preocupação em torno da epistemologia póscolonial como proposição outra de pensar as produções culturais de lugares postos em situação de exterioridade! ${ }^{4}$

\footnotetext{
${ }^{4}$ E é nesta ordem que, desde 2017, ano de realização da primeira edição do Seminário Latino-Americano de Estudos em Cultura - SEMLACult em Foz do Iguaçu/PR, Brasil, 2017, que organizamos (Bessa-Oliveira e Nolasco) como resultado do ST 05 - Fronteiras Culturais em Contextos Epistêmicos Descoloniais
} 
Tendências sempre são passíveis de existência! Na arte, na cultura e no conhecimento sempre vão haver possibilidades de tendências migrantes e/ou emergentes. Quero dizer que, graças às memórias, histórias, experiências, sujeitos, espaços e narrativas, particulares Biogeografias -, nós sempre teremos possibilidades infinitas de tendências na arte, na cultura e no conhecimento diferentes que emergem de tempos em tempos em lugares cada vez mais diferentes. No caso dos lugares periféricos, mais ainda, as tendências são sempre muito bem vindas e recebidas pela arte, pelas culturas e como modos de produção de conhecimentos que são recebidas, as tendências teóricas e teorias, sem ao menos transtraduzi-los para/nas culturas nas quais essas tendências aportam. Tem sido assim com as produções, as práticas, o ensino, e até mesmo com as teorias e teóricos brasileiros, por exemplo, nas características culturais e nos conhecimentos produzidos nessas margens, por conseguinte, também em relação ao que vem da Europa desde a colonização das Américas e com os aparatos que vêm dos Estados Unidos a partir da implementação da noção de mundo globalizado que migram para o(s) Sul(s). O(s) Sul(s) estão sempre na ordem de muitas culturas - multiculturais sempre tomadas da ideia de uma cultura latina, periférica e marginal improdutora de arte, cultura e conhecimentos pensados pela ótica nórdica ou norte-americana. ${ }^{5}$

Aponto tudo isso concordando, portanto, que no século XXI a rapidez e volatilidade dessas tendências são ainda maiores e que são cada vez mais simultâneas e até imediatistas, grassadas no advento dos tráfegos e tráficos (de gentes, mercadorias, culturas, imagens, representações etc) em lugares situados em zonas de fronteiras - em lugares de exterioridades ao pensamento hegemônico europeu - a exemplo de Mato Grosso do Sul! Nesses lugares, as tendências, de modo bastante geral, parecem encontrar lugar confortável, ninhos de plumagens, que as recebem de braços e bocas abertos sempre que essas querem vir, ficar e migrarem para dar lugar às outras novas tendências que serão lá produzidas. Portanto, cada

\footnotetext{
realizados naquele ano - o livro publicado em 2018 com o título Fronteiras Culturais em Contextos Epistêmicos Descoloniais. Tendo, os resultados ST 05 II, de 2018, o mesmo desejo a ser realizado. Visando sempre discutir as fronteiras que estão em emergência, nos diferentes contextos, nas culturas contemporâneas.

${ }^{5}$ A discussão sobre tendências aqui está aportada na ideia de que toda e qualquer novidade - teórica ou artística - vinda de lugares externos à América Latina nos serviu e ainda serve como modelo para pensar, fazer ou ensinar arte no Brasil. Seja pela ótica de teóricos que migraram para o exterior em busca de formação, seja pela visão daqueles que entendem que tudo que vem de fora é melhor do que o que é produzido dentro, tendências, nestes casos, consolidam a ideia equivocada - muito especialmente na Arte - de que tudo que parece com aquelas coroas colonizadoras é melhor e é a única forma de expressão, produção e conhecimento através da arte.
} 
paisagem biogeográfica, na ótica que se quer aqui entender a produção em Artes Visuais ${ }^{6}$, por exemplo, mas não somente, de lugares com essa natureza, que emerge e é produzida nesses lugares, carece obrigatoriamente de uma espécie de tendência (teórica e/ou teoria), na arte, na cultura, no conhecimento, para que seja compreendida melhor no contexto no qual estão emergindo essa arte, cultura e conhecimentos - por conseguinte os sujeitos dessas - a fim de significar essa produção ou situá-las para além e a partir de alguma tendência vinda de fora. Nesse sentido, a ideia deste trabalho também é discutir, ainda que sem pretensão de ser tomado como mais uma tendência migrante, a arte, a cultura e os conhecimentos - a partir das paisagens biogeográficas de Mato Grosso do Sul (Brasil) (BESSA-OLIVEIRA, 2016) - os postulados teóricos e artísticos que daqui estão emergindo ou que aqui estão sendo mantidos como modos de pensar a arte, a cultura e os conhecimentos locais como produtores de saberes com arte. ${ }^{7}$

Na América Latina, por conseguinte, parece que desde sempre as coisas se dão como tendências que ora servem para tratar da produção de arte e conhecimentos, ora servem para categorizar as culturas que vivem nesse lado "Sul" do Mundo Ocidental! Para fazer julgamentos de valores sobre arte, cultura e conhecimentos na América Latina, a grande maioria dos estudiosos das artes, das culturas e dos conhecimentos por aqui produzidos (quando esses são considerados como tais) tomam de tendências teóricas e/ou críticas sobre as artes, as culturas e os conhecimentos produzidos fora desse lócus para sustentar seus julgamentos analíticos. ${ }^{8}$ Quase sempre, para não reforçar a ideia de que se é desde sempre que

\footnotetext{
${ }^{6}$ Cabe, neste caso, para uma discussão mais ampla que o espaço deste artigo, consultar meu livro Paisagens Biográficas Pós-Coloniais: Retratos da Cultura Local Sul-Mato-Grossense (2018), que elabora, a partir de quatro artistas sul-mato-grossenses - Wega Ney, Henrique Spengler, Jorapimo e Ilton Silva - uma discussão e construção do conceito de paisagem biográfica pós-colonial, a fim de evidenciar "retratos" outros da cultura do Estado que esteve e está sempre muito incrementada a partir da imagem real e conceitual do boi através do bovinoculturismo.
}

\footnotetext{
${ }^{7}$ Importa dizer agora que as discussões sobre localização das produções e práticas artístico-culturais nos lugares específicos - através do conceito de biogeografia amplamente discutido por mim nos últimos anos - nem de longe se aproximam das discussões sobre os conceitos de regional ou regionalidade e/ou de nacionalismo tão abordados pelos teóricos e teorias brasileiros nos últimos anos do século XX. A ideia está agora posta em tratar das especificidades das diferentes práticas e produções artístico-culturais dos diferentes lugares, mesmo nacionais, que compõem o "universo" cultural brasileiro, mas sem a abordagem bairrista e provinciana, algumas vezes até canibalesca, que imperou naquelas abordagens feitas até os fins do século XX.
}

${ }^{8}$ No livro (Bessa-Oliveira (Org.). NAV(r)E - Pesquisa e Produção de Conhecimento em Arte na Universidade: artista, professor, pesquisador tem empreendido uma série de artigos que trabalham na contramão desta lógica cartesiana de produção de conhecimentos. Ou seja, todos os capítulos reunidos no livro estão ancorados em discussões epistêmicas outras que consolidam-se a partir das próprias práticas (artísticas, culturais e de 
se mantêm essa prática, a arte, a cultura e o conhecimento produzidos na Europa ou nos Estados Unidos que migram para a América Latina nos têm servido como tendências (teóricas, críticas, reflexivas, científicas, valorativas, estilísticas, memorialísticas, temporais, históricas, de produção, de ensino e até de sensação, etc) para analisar dissecadamente nossas artes, culturas e conhecimentos produzidos em solos latinos. ${ }^{9}$

Obviamente estou chamando de Mundo Ocidental à ideia que foi construída pelo Projeto Moderno Europeu arquitetado em meados dos séculos XV/XVI - apoiado pelo Cristianismo Católico como salvaguarda do mundo e que tem no Renascimento a noção maior de Arte - e que vai nesse ínterim projetar também o conceito de produção de conhecimento (Ciência) que reverbera até hoje: esses como únicos modos de produção para arte, cultura e conhecimentos para o resto do mundo. Pois, de modo contundente, a concepção de expansão de uma noção de arte, cultura e conhecimento maiores para o resto do mundo - através da colonização dos lugares "externos" àquela noção de mundo europeia - faz evidenciar, de lá para cá e até hoje, na América Latina, por exemplo, mas não somente, o entendimento de que as migrações teóricas, críticas, reflexivas, científicas, valorativas, estilísticas, memorialísticas, temporais e históricas devem ser compreendidas apenas como novas tendências para se pensar as diferentes culturas. Pois, compreendidos assim aqui, as imposições migrantes europeias e norte-americanas são tomadas como "benesses" à arte, cultura e conhecimentos latinos que são entendidos como lugares de culturas bugrescas. ${ }^{10}$

Tomo, portanto, como e de tendências para as discussões todas as correntes teóricas, críticas, reflexivas, científicas, valorativas, estilísticas, memorialísticas, temporais e históricas que migraram da Europa ou dos Estados Unidos, no caso do Brasil, nos últimos quinhentos anos e "insistentemente" - graças a nós mesmos - têm se fixado por aqui e vão, quando vão, bem como querem, embora para dar lugar a outras que acabam de chegar em substituição às

conhecimentos) emergentes em contextos dos mais diversos de situações de exterioridades para elaborar as argumentais ali expostas.

${ }^{9} \mathrm{O}$ dissecamento das produções não europeias e/ou norte-americanas (latinas) comparando-as àquelas tem sido prática recorrente na teoria e de teóricos latino-americanos ao abordarem nossas produções artístico-culturais. Desse prisma de reflexão, nós somos literalmente mal comparados aos europeus e/ou estadunidenses porque não somos aqueles e sequer somos aproximados do que verdadeiramente fomos: composição cultural da mistura entre indígenas, negros e europeus. Quer dizer, as análises artísticas buscam reconhecer na produção latina as características que as "aproximam" - que na verdade mais distanciam - das culturas colonizadoras e menos reconhecem em nós os fragmentos das culturas coloniais que somos.

${ }^{10}$ Para compreender a discussão sobre Cultura Bugresca ver o trabalho "Sobre a arte do agora em Mato Grosso do Sul: Biogeografia na cultura bugresca" apresentado no I SENELCO (2017). 
anteriores. Por conseguinte, a ideia não é tomar esta reflexão que aqui exponho como mais uma tendência, logo porque isso também seria possível. Pois, se tomadas como tendências, as reflexões pós-coloniais - reconhecidamente entendidas como pós-ocidentais - acabam por cair nos mesmos lugares das reflexões que emergiram após as formulações dos Estudos Culturais. Ou seja, se a epistemologia pós-colonial não for entendida como condição, no lugar de situação, por exemplo, acabamos por usar dela como mais um dos tantos "ismos" que aportaram e aportam ainda hoje na América Latina mal compreendidos pelas academias. ${ }^{11}$

A ideia é, por conseguinte, quando pensado aqui em pós-ocidentalismo/póscolonialismo, entender que as reflexões que são postas agora estão para além da ideia de sujeitos que foram colonizados historicamente porque ainda considero esse processo de colonização perfurante/perdurante na contemporaneidade. Portanto, daqui esboçam-se dois assuntos que vão ilustrar o lugar epistêmico que pretendo chegar: Primeiro é que pósocidentalismo/pós-colonialismo/descolonialismo ou pensamento descolonial não é o mesmo que uma continuação teórica após a ocidentalização do mundo. Ou seja, tomando o projeto de homogeneização do mundo construído pela cultura europeia dos séculos XV/XVI, as caravelas que deflagraram várias invasões mundo afora - no continente Americano, mas também no continente Africano e mesmo em alguns lugares orientais -, fazem constituir a noção que temos do mundo dividido em Ocidente e Oriente: um Planeta do duplo, dúbio e do comparável. Portanto, somos ocidentais grassados na ideia de mundo da Europa. Nesta ordem, a questão de ocidentalização do mundo tem a ver com colonização do pensamento e, logicamente, da produção em arte, das culturas e dos conhecimentos dos lugares por onde essas caravelas aportaram. ${ }^{12}$ Igualmente, esses lugares coloniais continuam (re)produzindo, quase na grande maioria, arte, cultura e conhecimentos baseados em modelos construídos faz quase dez séculos.

Ocidentalização do mundo, nesta ótica, corresponde a dizer que não tivemos ou temos opção de participar ou não desta narrativa global que hoje é difundida pelo poder Estadunidense ancorado pelo projeto de globalização do mundo. Nesse sentido, temos dois projetos de homogeneização/globalização, atualizando as questões em pleno século XXI, que

\footnotetext{
${ }^{11}$ Não vou argumentar a favor da impossibilidade dessa tendência! Pois, como é de praxe no Brasil, até mesmo a teoria pós-colonial tem tomado o lugar da noção de pós-colonialismo como epistemologia pós-ocidental de perspectiva geoistoriográfica.

${ }^{12}$ Do mesmo jeito desocidentalizar o mundo é o mesmo que descolonizar o pensamento e o modo de produção em arte, de compreender as culturas e os conhecimentos de lugares que foram relegados a lugares dos "confins do mundo".
} 
imperam para a construção de um planeta unívoco na produção, no pensamento e no reconhecimento do que é arte, cultura e conhecimento produzidos apenas por determinados sujeitos, lugares e línguas. Quero dizer que a tendência de arte, cultura e conhecimento estaria ancorada nesta ideia de homogeneização do planeta e em um só tipo e/ou pensamento do que seja arte, do que seja cultura e do que seja produção de conhecimento. De maneira oposta, portanto, pensar em mundo pós-ocidental é compreender que não pensamos depois de algum pensamento anterior. Mas é tomar da consciência de que a colonização é uma sistematização colonialista até do pensamento emocional, dirá então racional, que impera nas culturas dos lugares, sujeitos e conhecimentos já colonizados que foram divididos em dois.

Esse pensamento (pós-ocidental ou pós-colonial) demonstra, por exemplo, que o mundo não vai se constituir única e exclusivamente na ideia de que o berço da humanidade é a Grécia; que a Ciência produzida pela divisão do cérebro em razão e emoção não constitui a totalidade dos saberes de sujeitos, lugares e línguas que não são os autores da constituição desse pensamento hegemônico. Igualmente pós-ocidentalizar o pensamento é reconhecer que a arte, a cultura e o conhecimento não estão circunscritos a uma determinada língua, a um lugar particular e menos ainda a um determinado momento histórico inalcançável por lugares e línguas que não são aquelas. A tendência epistêmica pós-ocidental, neste sentido, não se tornará mais uma tendência epistêmica como pensam alguns "eleitores balssonarianos" - para não falar de porcos chauvinistas - que assim entenderam os Estudos Culturais, os Estudos da Desconstrução e outros Estudos que tentaram desfazer a ideia de Mundo Ocidental deles. Pois paisagem biogeográfica, na ordem aqui em discussão, está em não ser mais tendência, mas ser uma condição para pensar as nossas produções em arte, as culturas e os conhecimentos produzidos por lugares não considerados (lugares inexistentes) pelo pensamento hegemônico aquém da ideia de colônias, mas que produzem arte, cultura e conhecimentos bugrescos, por exemplo. Portanto, são lugares de Cultura Bugresca! ${ }^{13}$

Tendências, portanto, neste caso, sempre vão ser passíveis de existência! $\mathrm{Na}$ arte, na cultura e no conhecimento sempre deve haver possibilidades de tendências para que possamos

\footnotetext{
${ }^{13}$ No caso da minha discussão exposta, ainda, a ideia está circunscrita à fronteira como lugar epistêmico e de exterioridade aos pensamentos hegemônicos europeus e estadunidenses (geográfico e cultural). E neste sentido, a ideia de exterioridade coloca esta reflexão além de qualquer noção binário de compressão de arte, culturas e produção de conhecimentos assentados em saberes disciplinares até hoje evidenciados pelas academias brasileiras sobre esses. Portanto, pensar em específicos objetos de arte, culturas e conhecimentos não é o mesmo que pensar em especificidades artísticas, culturais e de produzir conhecimentos a partir dos próprios conhecimentos.
} 
construir discursos que representem os lugares de onde as tendências emergem; nunca o contrário. Tendência teórica tem que ser igual às tendências da arte, as mudanças culturais e às diferentes produções de conhecimentos. Quero dizer que, graças às memórias, histórias, experiências, sujeitos, espaços e narrativas particulares - o que tenho e venho chamando de Biogeografias: bio-sujeitos, geo-espaços, grafias-narrativas dos sujeitos, lugares e narrativas diferentes da ideia dos modelos até hoje impostos -, nós sempre teremos possibilidades infinitas de pensar em tendências na arte, na cultura e no conhecimento diferentes que emergem de tempos em tempos no conceito de história que temos. Neste caso, obriga-me reforçar a concordância com a ideia de que em nosso século XXI ainda mais a rapidez e emergências do que nos parece tendências são cada vez mais ágeis e até muito mais bem recebidas pela crítica! Há uma plêiade que faz boa aceitação nos sistemas da arte de tendências! As tendências aparecem até com faces de urgências! Logo, cada paisagem biogeográfica na cultura contemporânea, como tento pensar as produções dos lugares, deste lugar pós-ocidental/pós-colonial/descolonial que estabeleço a partir dos processos coloniais históricos e contemporâneos, vai carecer obrigatoriamente, de forma concordante com as possibilidades de tendências, de uma espécie de tendência (epistêmica), na arte, na cultura, no conhecimento, para que sejam compreendidos melhor como a arte, a cultura e o conhecimento produzidos nos contextos nos quais estão emergindo. Ao contrário do que está imposto até hoje nas culturas de exterioridade, está reflexão nunca estabelece uma "noção" de comparação como aquelas tendências que aportaram por aqui até hoje propuseram.

O segundo assunto que me leva ao lugar epistêmico almejado é que a produção artística vai "ilustrar" as discussões teóricas como pano de fundo para vislumbrar quem produz ou quem reproduz tendências artísticas migrantes em solo sul-mato-grossense, por exemplo, mas, do mesmo jeito, ilustrarão quem reproduz tendências teóricas para manutenção de algumas reproduções na cultura local. Deste ponto, a ideia é discutir, ainda que sem pretensão que essas discussões sejam tomadas como uma tendência (vou advertir isto sempre), a arte, a cultura e os conhecimentos - a partir das paisagens biogeográficas construídas e constituídas em e de Mato Grosso do Sul (Brasil) - e os postulados teóricos e artísticos que daqui estão emergindo ou que aqui estão sendo mantidos como modos de pensar a arte, a cultura e os conhecimentos locais para o resto do mundo. ${ }^{14}$ Para tanto, não fugindo à

\footnotetext{
${ }^{14}$ Em outros trabalhos já publicados fiz discussões que evidenciam muito bem esta questão na arte local sulmato-grossense desde a divisão em 1977 de Mato Grosso. Quer seja temos artistas que estão produzindo desde então a fim de manterem-se no "sistema" de arte local; temos artistas que são excluídos porque não participam
} 
minha regra de nunca querer esta reflexão como mais uma tendência para as produções em arte, para a cultura ou para os conhecimentos que daqui emergem, tomo das epistemologias culturais - pós-ocidentais fronteiriças - que emergiram e têm sido cada vez mais consolidadas nos lugares emergentes latino-americanos para discutir essas supostas tendências de arte, cultura e conhecimentos. Pois, dessas produções teóricas e artísticas de lugares como paisagens biogeográficas outras - pensando-as como emergências dos lugares, sujeitos e línguas não hegemônicas - é que se torna possível estabelecer possibilidades (artísticas e/ou teóricas) de reflexões não como tendências na arte, na cultura e no conhecimento de Mato Grosso do Sul ou de qualquer outro lugar epistêmico divergente das paisagens clássicas e/ou modernas construídas pelo pensamento europeu e reforçadas na atualidade pelo capital estadunidense nas culturas periféricas.

\section{Continuação do desenvolvimento das questões de tendências em Arte}

Tomando como mote a noção de que a academia ainda postula que os clássicos são essenciais e os únicos fundamentais: teóricos e teorias que migram dos lugares reconhecidos como centros epistêmicos, quase sempre a Europa e/ou os Estados Unidos, a ideia aqui é estabelecer, a partir de reflexões descoloniais e/ou a partir do que tenho chamado de Estudos de Culturas, uma discussão acerca das práticas em arte - teórica, pedagógica e de produção que sustentam o ser, sentir, saber (GÓMEZ MORENO; MIGNOLO, 2012) como única forma de descolonização do saber, conhecer e poder dos lugares colonizados pelo/do projeto hegemônico europeu, a exemplo de Mato Grosso do Sul circunscrito na América Latina. Ou seja, sem ser tomado como mais uma tendência teórico-crítica que se aporta na América Latina migrando como "bom vento" que corporifica ao corpus europeu em nossa arte, cultura e conhecimentos, o pensamento pós-colonial fronteiriço aqui é tomado como única condição para "aprender a desaprender a re-aprender de outra forma, [...]" (MIGNOLO, 2014, p. 7) tudo que nos fora (im)posto como nosso pela História da Arte europeia sempre contada como tradição para a arte do "resto do mundo".

Aprioristicamente, se por um lado as discussões estarão ancoradas nas Artes Visuais de fronteira - essa última tomada como lugar que foi constituído para separar, mas também é lugar de reunião das diferenças ex-ternas aos discursos do poder. Por outro lado, como não o poderia ser diferente, as discussões tomam também de uma ideia de corpo-fronteira - ou

desses mesmos "sistemas" de arte, e ainda temos artistas que produzem mais do mesmo a fim de se inscreverem nesse suposto sistema da arte que conglomera um mercado global. 
corpo em estado constante de fronteira - na produção cênica local - que corporifica uma ideia outra de corpo que, por conseguinte, é um corpo que $s i$-move-se como quer. ${ }^{15} \mathrm{Ou}$ seja, das Artes Visuais às produções em Dança, Teatro e/ou Performance, as discussões tomarão da ideia de esta(r)do de/em/da fronteira para pensar as "diferenças coloniais” (MIGNOLO, 2003) que não são contempladas pelas teorias e teóricos que migram com os pensamentos hegemônicos para as culturas periféricas. Quer dizer, o esta(r)do de/em/da fronteira ${ }^{16}$ nas Artes Visuais e/ou nas Artes da Cena nessas discussões serão privilegiados para ressaltar que somente dão conta desse(s) estado de "corpo-fronteira" uma "tendência" teórica que também se encontra na mesma situação: ou seja, uma teoria que emerge dessa condição imagética de ex-terno ${ }^{17}$ ao contexto de fronteira.

Tomando das epistemologias culturais - o que tenho trabalhando recentemente como Estudos de Culturas - que emergiram e têm sido cada vez mais consolidadas nos lugares emergentes latino-americanos que têm prática descolonial, esta noção está ancorada na ideia de que quanto mais sou possibilitado em ampliar a leitura sobre e a partir das próprias práticas culturais emergentes e de exterioridade, mais as teorias - mesmo migrantes - me servem. A diferença é que não tomo exclusivamente dos pensamentos migrantes para. Pois, dessas produções teóricas e artísticas de lugares com paisagens biogeográficas outras é que se tornará possível estabelecer possibilidades de tendências teóricas e artísticas (igualmente analíticas) na arte, na cultura e no conhecimento de Mato Grosso do Sul que de fato (re)signifiquem as práticas culturais de lugares com natureza imposta de exclusão divergente das paisagens clássicas e/ou modernas erigidas como nossas pelo pensamento europeu do século XV. Quero, portanto, pensar em emergência epistêmica desse lugar de fronteira Brasil-Paraguai-Bolívia - como lugar de produção de arte, cultura e conhecimentos.

As vozes pós-coloniais, ou melhor dizendo, as vozes dos sujeitos subalternizados pelo pensamento hegemônico europeu ou pelo sistema capitalista estadunidense emergem exatamente porque ainda são, pelo primeiro e pelo último, mantidos como os mesmos sujeitos que por aqui foram encontrados ou trazidos à força por volta de 1500. Igualmente, a produção

\footnotetext{
${ }^{15}$ A reflexão sobre um corpo que si-move-se como quer está posta em diferentes outros textos meus. Para melhor compreender a ideia vale conferir: BESSA-OLIVEIRA; NORONHA, 2016; BESSA-OLIVEIRA, 2016; $2017 ; 2018$.

${ }^{16} \mathrm{O}$ esta(r)do de/em/da fronteira é uma analogia a condição/situação de estado e estar de um corpo outro de/em/da fronteira (geográfica e epistêmica) impostos pelo pensamento moderno.

${ }^{17}$ Tanto uma condição ex-terna ou ex-terno - no plural ou singular - como situados aqui, estão para a noção de corpos outros que forma impostos e que são emergentes de/em/da fronteira.
} 
artística, cultural e de conhecimento latino-americana, por conseguinte as brasileiras e mais precisamente as sul-mato-grossenses, estão, desde então, sendo pensadas a partir desse discurso homogeneizador que fez as vozes emergirem. Ou seja, se por um lado as vozes subalternas hoje já gritam, balbuciam ou falam por si mesmas em algumas situações poucas, por outro lado esses mesmos sujeitos subalternos são silenciados pelas vozes imperantes dos discursos hegemônicos ou simplesmente alguns desses mesmos subalternos reproduzem os discursos hegemônicos situando suas próprias práticas artísticas, culturas e conhecimentos exclusivamente a partir das produções de arte, cultura e conhecimentos dos donos dos discursos hegemônicos imperantes.

Portanto, quando pensamos na arte sul-mato-grossense, por exemplo, emergem desse modelo de discussão três situações diferentes: $1^{\mathrm{a}}$ - uma produção que toma dos discursos dos sujeitos subalternizados para fazer emergir arte, cultura e conhecimento indistintamente da aprovação e/ou reconhecimento do discurso hegemônico; $2^{\mathrm{a}}$ - uma produção que se ancora no discurso hegemônico para garantir lugar de arte como reconhecida pelo discurso hegemônico; $3^{a}$ - uma produção que é avalizada pelo Poder Público para que se faça reconhecer algumas produções como arte, a fim de sustentar que esse lócus produz uma "arte" "específica" que emergiria das vozes subalternas, mas que está, na verdade, em constante relação com os discursos hegemônicos tendenciosos do que seja arte, cultura e conhecimentos. Cabe a pergunta: e o resto do Brasil,então, onde fica? Dessas três situações apontadas, portanto, cabendo dizer antes que estou situando-as na prática artística, na teoria e crítica de arte e também no ensino de arte - sobre a arte, a cultura e o conhecimento - produzidos em Mato Grosso do Sul, pois compreendo que as tendências imperantes neste lócus enunciativo estão para ambas as habilidades com a arte, a pergunta é condição para toda a reflexão.

O pensamento pós-colonial/pós-ocidental/descolonial, como têm sido nominado por alguns de seus autores, diferentemente da ideia equivocada entendida por alguns desinformados, não tem nenhuma relação direta com referências pós-modernas estadunidenses. Obviamente, então, estão menos ainda relacionados, com sentido de favorecimento, com a consciência moderna europeia. Do mesmo jeito, o que venho conseguindo chamar de paisagem biogeográfica ou de cultura bugresca não têm relações também de continuidades com o pensamento pós-moderno ou o pensamento moderno. Do mesmo jeito esses não estão para a ideia de situação pós-colonizados! Dessa forma, paisagem biogeográfica ou cultura bugresca devem ser compreendidos como pensamentos epistêmicos outros que emergem da fronteira sul do Centro-Oestre brasileiro para pensar as práticas 
culturais através da arte desse específico lugar; fato que pode e deve ocorrer, respeitando as devidas especificidades, de qualquer lugar outro geográfico e histórico que fora relegado pelos pensamentos modernos e pós-modernos e que seja tomado como lugar epistêmico a partir das suas especificidades porque fora desconsiderado pelos Projetos europeu ou estadunidense como produtores de alguma coisa.

Daí então se esboça a ideia de que qualquer sujeito, lugar e narrativa (artísticocultural) são tomados como produtores de arte, cultura e conhecimentos a partir das suas biogeografias, que são específicas, e que, por conseguinte, demandam de operações epistêmicas outras (múltiplas, variadas, inventadas, tendenciosas, etc), não binárias, - não de tendências migrantes - que contemplem as especificidades das suas produções/práticas artístico-culturais, por exemplo, que também não foram contempladas nos/pelos Projetos hegemônicos de constituição de "um" mundo homogênio universal. Pois, ambas as ideias, modernas e pós-modernas, de homogeneização do planeta não levaram em consideração (desconsideraram a existência de) vários mundos outros que hoje são circunscritos sabiamente na rubrica de sujeitos, lugares e narrativas subalternizados. Pois, esta rubrica está posta para aqueles sujeitos, lugares e narrativas que não têm voz e vez ou para os que são ditos (relatados e/ou descritos $=$ analizados) através ou pelos outros discursos dos poderes (políticos, econômicos e culturais) que têm poder de voz e que sempre são donos da vez.

Obviamente, a matriz colonial, em sua primeira formulação, não era um esquema sagrado e imobilizador, mas uma proposta flexível e orientadora para analisar a formação, manutenção e transformação da gestão imperial/colonial do poder. É importante notar que entendemos a matriz de poder colonial não só como o sistema de controle das colônias e ex-colônias (isto é, do mundo não europeu e não americano), mas como o que está em vigor e na base da ordem global. (MIGNOLO, 2009, p. 7-8) ${ }^{18}$ (Tradução livre minha)

Nesta direção ex-posta por Mignolo, deve-se compreender que tanto o pensamento póscolonial/pós-ocidental/descolonial, bem como a noção de paisagem biogeográfica ou de cultura bugresca, além de não poderem ser compreendidos como continuísmos de quaisquer outros pensamentos epistêmicos anteriores que migraram mundos afora lendo e analisando arte, cultura e conhecimentos outros, esses também não descartam a insistência de continuidade dos pensamentos epistêmicos modernos e pós-modernos migrantes como

\footnotetext{
18 "Obviamente, la matriz colonial, en su primera formulación no fue un esquema sagrado e inamovible sino una propuesta flexible y orientadora para analizar la formación, mantenimiento y transformación del manejo imperial/colonial del poder. Es importante señalar que entendemos la matriz colonial de poder no sólo como el sistema de control de las colonias y ex colonias (esto es, del mundo no-Europeo y no-U.S.) sino como el que se encuentra vigente y en la base del orden global." (MIGNOLO, 2009, p. 7-8)
} 
tendências nos lugares subalternizados. Bem como ambos ainda levam em consideração que os Projetos Coloniais se reverberam na arte, na cultura e nos conhecimentos produzidos, na grande maioria, pelos sujeitos, nos lugares e através das narrativas contemporâneas subalternizados por esses próprios Projetos hegemônicos.

A tendência que se quer aqui circunscrita a partir do pensamento epistêmico descolonial que emerge dessa fronteira tríplice internacional - Brasil(Mato Grosso do Sul)/Paraguai/Bolívia - e dos limites nacionais com Minas Gerais, São Paulo, Paraná, Goiás e Mato Grosso (de quem, no caso deste último, numa divisão política, econômica e mesmo cultural o estado de MS é criado em 1977), é que sejam tomadas as especificidades da arte, da cultura e do conhecimento produzidos nesses locais para pensar a si próprios. Quer dizer, desancorando-se das ideias modernas de regional ou regionalismo, que também são conceitos que devem suas lógicas estabelecidas hoje aos pensamentos modernos e/ou pós-modernos migrantes, o pensamento epistêmico outro como tendência da arte, da cultura e do conhecimento produzidos em lugares subalternos fará evidenciar as diferenças coloniais, entendidas a partir das diversalidades e com as sensibilidades ocupando o lugar de estéticas que sustentam as probabilidades de padrões nas produções e práticas artístico-culturais periféricas (ancorados nos jargões de erudito, clássico, cânone, estético, sublime, essencial ao espírito, etc) que migram de um único lugar para muitos outros como formas únicas de pensar a arte, a cultura e os conhecimentos produzidos por mundos outros. ${ }^{19}$

Assim, as biogeografias ou as paisagens biogeográficas não podem ser compreendidas como tendências teóricas e/ou artísticas pura e simplesmente que migraram de algum lugar além mar. Pois ambas são reflexões que emergem do que chamei de "esta(r)do de/em/da" e agora na fronteira. Portanto, são epistemes outras que grassam da desgraça - para uns - de ser sujeito de fronteira. De ser sujeito posto em estado de fronteira. Por conseguinte de ser um corpo outro por ser um corpo em esta(r)do de/em/da/na fronteira-sul do CentroOeste brasileiro. Nesta lógica, por conseguinte, ainda não houve ou haverá tendência migrada da Europa e/ou dos Estados Unidos que dê conta de compreender porque somos diferentes: e está lógica está em compreender que é porque grassamos de uma diferença colonial.

\section{Conclusões - Arte e Práticas artístico-culturais em contextos fronteiriços}

\footnotetext{
${ }^{19}$ Sobre esta última questão vale a leitura do texto "Para experimentar, formar, praticar, caminhar é preciso antes ser, sentir, saber bio-geo-grafias no ensino de artes" apresentado na Mesa 5 "Caminhos rompidos: Pensamento descolonial no ensino de Arte” e publicado nos Anais (páginas 240-256) do XXVII CONFAEB. Disponível em: http://faeb.com.br/anais-confaebs.html.
} 
Os lugares em situação externa ao pensamento hegemônico europeu, como venho dizendo, estiveram e estão sempre em esta(r)do de/em/da e na fronteira desde 1500. A ideia de descobrimento assombra as práticas culturais desses lugares externos desde sempre. Por conseguinte, os corpos-fronteira, quase constantemente, sempre estão ancorados em ideias binárias de composição cênicas: um corpo para. Nas Artes Visuais a problemática parece ainda maior considerando que impera um fazer paisagístico local sempre ancorado nas mesmas proposições visuais renascentistas estabelecidas no século XV. Dessa forma, é imprescindível saber, sem serem tendências, como as produções locais artístico-culturais estão recebendo as proposições tendenciosas do mundo contemporâneo: como leis que garantem às práticas artísticas lugar de situação ou lugar de exposição? Pois, salvos poucos casos, os teóricos e artistas locais sul-mato-grossenses contribuem mais com as tendências de exclusão das artes locais do que com as epistemologias que emergem desses lugares.

A partir desse momento, e percebemos claramente no Kant de Observaciones sobre lo bello y lo sublime (1776, sección IV), quanto mais o pensamento da Europa vai para o sul e para o Oriente e atinge a Ásia, África e América, menos parece ser - por essa maneira de pensar - a capacidade das populações não europeias de sentir o belo e o sublime estético. Poderíamos até pensar que as sensações dos Antigos Maias e Incas ante a Selva e os Andes, em sua proximidade com a magnificência dos relâmpagos e dos trovões, não experimentaram o sublime, mas talvez certas sensações "primitivas" que não chegavam àquela dimensão estética. Estou imaginando claro, mas a verdade é que o estético e o conceito secular de razão andam de mãos dadas e cumprem duas funções complementares: a) na Europa começa a construir uma subjetividade secular e burguesa que é separada da subjetividade sagrada e teológica construída a partir da Renascença e liderada pelos países do sul e, b) fora da Europa, a estética emerge como um novo conceito e critério para (des)avaliar e hierarquizar a criatividade sensorial de outras civilizações. Assim aparece o critério de que uma "tela" é arte e um objeto de argila "artesanato". (MIGNOLO, 2009, p.10-11) ${ }^{20}$ (Tradução livre minha)

Com as tendências teórico-críticas migraram também para os mundos subalternos as noções de arte, cultura e conhecimentos - reconhecidos como melhores pela ideia de beleza e sublimação - vindos também dos países Primeiro-mundistas. De modo nada peculiar a beleza

\footnotetext{
20 "A partir de ese momento, y lo percibimos con nitidez en el Kant de Observaciones sobre lo bello y lo sublime (1776, sección IV), cuanto más va el pensamiento de Europa hacia el sur y hacia Oriente y llega a Asia, África y América, menor parece ser- para este modo de pensar- la capacidad de las poblaciones no europeas de sentir lo bello y lo sublime estético. Hasta se podría pensar que las sensaciones de los Antiguos Mayas e Incas ante la Selva y los Andes, en su cercanía a la magnificencia de los rayos y los truenos no experimentaban lo sublime sino quizás ciertas sensaciones "primitivas" que no llegaban a cuajar en la dimensión estética. Estoy imaginando claro, pero lo cierto es que lo estético y el concepto secular de razón van de la mano y cumplen dos funciones complementarias: a) en Europa se comienza a construir una subjetividad secular y burguesa que se separa de la subjetividad sagrada y teológica construida a partir del Renacimiento y liderada por los países del sur y, b) fuera de Europa, la estética emerge como un nuevo concepto y criterio para (de)evaluar y jerarquizar la creatividad sensorial de otras civilizaciones. Así aparece el criterio de que una "tela" es arte y un objeto de arcilla "artesanía"." (MIGNOLO, 2009, p.10-11)
} 
e a sublimação estéticas europeias acabaram por arraigarem-se nas artes das culturas periféricas espalhadas pelos continentes Asiático, Africano, Americano e Oriental - ressalvase que são todos os nomes noções de mundos nominadas pelos Projetos hegemônicos porque essas não eram, são e serão capazes de sentir a bela e sublime estética produzida única e exclusivamente na Europa. Ou seja, os outros continentes todos, bem como parte da própria Europa e desconsiderando apenas os Estados Unidos nas Américas, ninguém produziu estética singular suficientemente igual àquela. $\mathrm{O}$ fato até é verdade se tomarmos da ideia tão aqui ressaltada de que nenhum lugar produz arte, cultura e conhecimentos iguais a outro lugar. Verdade também o seria se tomássemos da compreensão do pensamento moderno como única forma de compreender as práticas artístico-culturais e a produção de conhecimentos de culturas diferentes das várias culturas europeias - agora a ideia de diferença já está ancorada no entendimento de diverso a partir de diversalidade - seria muita ingenuidade: pois, se adverte também que, no entanto, nem mesmo o Projeto Moderno Europeu toma da ideia de várias Europas dentro daquele continente.

Mas, por último, será uma enorme e absurda mentira contada desde o século XV, reforçada por Kant (1776) como mostrou a passagem anterior de Walter Mignolo, de que os sujeitos não europeus ou não estadunidenses não conseguem sentir uma bela e sublime estética se tomarmos da ideia de ambas como diferentes a partir das suas sensibilidades biográficas, das suas diversalidades, do seu lócus de enunciação migrante que vão, por conseguinte, fazer emergir epistemologias (críticas, teóricas, artísticas, pedagógicas) outras para compreensão da arte, cultura e conhecimentos outros que emergem desses muitos lugares; que são biogeografias particulares que têm memórias, histórias, experiências, sujeitos, espaços e narrativas - Bio-sujeitos, geo-espaços, grafias-narrativas = Biogeografias , diferentes e até divergentes que sempre deverão ter infinitas tendências na arte, na cultura e no conhecimento e que emergem de tempos em tempos, mas nos próprios lugares onde essas estão emergindo. Não seriam epistemologias que migraram para esses vários lugares a fim de serem possibilidades de pensar sobre as práticas artístico-culturais que emergem desses lugares, mas, seriam, na verdade, epistemes dos lugares para esses próprios lugares.

Pensar na produção local, seja provinciana, nacional ou continental, da exterioridade do modelo moderno-ocidental exige modificar o lugar a partir do qual pensamos a nós mesmos e a partir do qual olhamos para o mundo. De todos os locais "periféricos" - isto é, externos à razão moderna eurocêntrica - surgem pesquisas semelhantes, particularmente nas últimas colônias que rompem com a sujeição política aos impérios (Índia, África, Oriente). A América Latina, em suas diferentes latitudes, não é excluída dessa emergência de alternativas [epistêmicas] ao poder hegemônico, com uma diferença fundamental: nesta porção mais ao sul do continente, as apostas do pensamento e da produção autônomos já possuem uma 
genealogia de mais de 500 anos. (PALERMO, 2009, p. 15-16) ${ }^{21}$ (Tradução livre minha)

E a grande verdade da história toda que não fora contatada está ai: há uma ascendência artística, cultural e de conhecimentos na América Latina que antecede aos 500 anos de história que têm a Europa como narradora mor. Mas verdade maior é que essa narrativa se "esqueceu” de levar em consideração esses "corpos” todos outros. E verdade ainda maior que todas essas é que vários, muitos desses corpos latino-americanos ainda insistem em achar que supostamente produzem arte, cultura e conhecimentos que são reconhecidos pela narrativa que tem o centro na Europa. Ou ainda vivem crentes no fato de que são heranças culturais (doce ilusão que não se veem como heranças coloniais que são) daqueles e que, por isso, devem produzir arte, ser cultura e travar diálogos intimistas com os mesmos conhecimentos (tendências) vindos daquele outro lado do Atlântico.

As "escolas" - em suas duas dimensões ocidentais: como centros de aquisição de conhecimento e como correntes estéticas - são instaladas e geram os critérios de validação que terão que reger [as normas] por mais de cinco séculos. Descartaram as produções das culturas preexistentes e consideradas apenas pelo seu autoctonismo disfarce de desvalorização diante da "universalidade" das obras que são canonizadas - as que se originam neste cone do mundo [América Latina] não devem apenas se adaptar aos "modelos" externos, mas sempre serão vistas como "assincrônicas" em relação a estes já que as características de inovação chegam sempre atrasadas e, em geral, sem a sua "pureza" e "autenticidade" [em relação àquelas]. (PALERMO, 2009, p. 17) ${ }^{22}$ (Tradução livre minha)

As culturas preexistentes na América Latina foram desconsideradas pela cultura europeia que varreu os outros mundos em busca de riquezas minerais/naturais, mas também a fim de implantação das suas características (artísticas, culturais, políticas, educacionais, econômicas etc) como únicas formas de governanças possíveis e como reforço de uma

\footnotetext{
21 "Pensar la producción local, ya sea ésta provincial, nacional o continental, desde la exterioridad del modelo moderno-occidental requiere modificar el lugar desde el que nos pensamos a nosotros mismos y desde el que miramos el mundo. Desde todas las localizaciones "periféricas" -es decir exteriores a la razón eurocéntricaemergen búsquedas similares, partiuclarmente en las últimas colonias que rompieron con la sujeción política a los imperios (India, África, el Oriente). América Latina, en sus distintas latitudes, no queda fuera de esta emergencia de alternativas al poder hegemónico, con una diferencia fundamental: en este sudcontinente las apuestas de pensamiento y producción autonómicas tiene ya una genealogía de más de 500 años." (MIGNOLO, 2009 , p. 7-8)

22 "Las "escuelas" -en sus dos dimensiones occidentales: como centros de adquisición de conocimientos y como corrientes estéticas- se instalan y generan los criterios de validación que habrán de regir durante más de cinco siglos. Descartadas las producciones de las culturas preexistentes y consideradas sólo por su autoctonismo -rasgo de disvalor frente a "universalidad" de las obras que se canonizan- las que se originan en este cono del mundo no sólo deben edecuar-se a los "modelos" exteriores, sino que siempre se verán como "asíncrónicas" por relación a éstos ya que los rasgos de innovación llegan tarde y, por lo general, sin su "pureza" y "autenticidad"." (PALERMO, 2009, p. 17)
} 
suposta hegemonia cultural fantasiada de igualdade universal. Como se esses múltiplos outros lugares não tivessem suas próprias formas de sobrevivências - lembremos que não cabe mais discutir se o que fora trazido ou o que ficou nos foi e é válido ou inválido na atualidade vamos olhar para frente e ver se aquelas governanças que nos foram relegadas nos continuam servindo como formas únicas (através das desculpas de serem tendências) para pensar a nós próprios nos fazeres com a arte, a partir de nossas formas de culturas e sobre as produções de conhecimentos que fazemos daqui emergir. Nesse sentido, não cabe mais uma crítica pura e simplista ao pensamento e ao Projeto Moderno Europeu, bem como não cabe mais uma crítica velada ao capital vivendo sobre o mesmo teto que eles. A tendência crítica que se quer aqui está sub judice da crítica de fora (da exterioridade) desse pensamento e/ou consciência modernos: quer-se uma crítica de fronteira. Pois aqueles que estão sob ele (Pensamento Moderno), a fim de tratar a arte, mesmo a rotulada de contemporânea - que, aliás, estou chegando à conclusão de que o termo é mais um "estilismo" artístico importado - que continuem dizendo que produzimos arte, a meu ver mal e porcamente, porque é mais do mesmo e como cópia sem "pureza” e "autenticidade”, porque somos "iguais" aqueles.

A ideia de cultura bugresca que tenho discutindo, por fim, está posta em relação às culturas não circunscritas em lugares, datas, histórias, memórias, experiências e línguas hegemônicas específicas e que foram submissadas às culturas europeias e estadunidenses ao longo dos séculos. Igualmente para as discussões que venho de uns anos para cá nominando de "estética bugresca", o termo acaba por sofrer alterações de nomenclatura exatamente visando não falar mais do mesmo: sensação como estética. Assim como as culturas, práticas culturais e artísticas e também os conhecimentos que não se estancam em possibilidades exclusivistas e únicas, passo a pensar em "estética (ou não) bugresca" primeiro - esta noção tendo em vista a ideia de que ao discutir uma possibilidade epistêmica outra para pensar as práticas culturais bugrescas (de lugares da exterioridade) seria coerente pensar em um termo que suplantasse o imaginário conceitual do termo estética que temos arraigado na cultura ocidental de pensamento Moderno europeu. Mas, agora, de certo tempo para cá, tenho tratado nessas discussões epistêmicas a arte, a cultura e os conhecimentos desses lugares, tendo Mato Grosso do Sul sempre como o meu ponto de partida, a partir do termo cultura bugresca.

Venho me valendo do termo cultura bugresca, pois, considero que cultura não é estética! Ao menos estética como a noção cimentada na cultura ocidental que temos a mais de 500 anos. Pensar em culturas, no mínimo, demandariam várias estéticas - portanto, tendências possíveis de pensar as suas práticas culturais outras. Pois, tendência está para possibilidade 
que tende a algo, mas está também para convergência a outras coisas. Mas já que, ainda, considerando essa multiplicidade de culturas e práticas, especialmente em Mato Grosso do Sul de onde emergem os pontos dos quais faço pontes aqui para as discussões, o termo “cultura" amplia qualquer noção imaginável do conceito dessa ideia eurocêntrica de estética: uma ampliação que vai perfurar, por conseguinte, qualquer noção de tempo, lugar e língua específicos como maiores/melhores nas produções artísticas pós-ocidentais/póscoloniais/descoloniais. Deste modo, agora as discussões circundam os termos prognósticos, lugares e autoinscrições das práticas culturais, artistas e dos discursos tendo em vista sua inscrição ou não como prática de culturas bugrescas. ${ }^{23} \mathrm{E}$, deste modo, falo em Cultura Bugresca de Mato Grosso do Sul, assim como poderia estar falando de cultura bugresca de qualquer outro lugar considerado não hegemônico ou externo ao pensamento hegemônico europeu, não estético como pensaram os gregos, não datado, não artístico, não cultural específicos como suplantam as mesmas ideias do Projeto Moderno europeu ou Pós-Moderno estadunidense. Do mesmo jeito falo em Paisagens Biogeográficas porque as imagens que são geradas daqui são diferentes de qualquer lugar outro do planeta.

Mato Grosso do Sul, na arte, quase de modo geral, continuo sem a intenção de generalizar, pois acredito em mudanças, ainda tem sua promoção sustentada (precariamente) no Poder Público: Municipais e Estadual, normalmente, mas em alguns parcos casos alguns artistas nas diferentes linguagens conseguem algum apoio Federal. ${ }^{24}$ Este ponto é fator importante para situar (a contemporaneidade ou $d a$ atualidade) as práticas artísticas locais no que tange às representações e visualidades que essas exprimem. Sabe-se desde muito tempo (do clássico ao moderno) que obras avalizadas por poderes instituídos (políticos, econômicos e/ou religiosos) privilegiam imagens e discursos também institucionais nelas. E neste caso, os artistas locais em sua grande maioria tomam nas suas produções de um discurso identitário

\footnotetext{
${ }^{23}$ Uma discussão mais ampla sobre o lugar que os artistas ocupam no cenário artístico sul-mato-grossense está melhor exposta no texto "EM TEMPOS DE AGORAS (Agouro, Ágora, Agora), AINDA VIVEMOS NO PASSADO?" apresentado na XII edição do "Ciclo de Investigações do Programa de Pós-Graduação em Artes Visuais", realizado na cidade de Florianópolis-SC na Universidade do Estado de Santa Catarina (UDESC), vinculado ao Centro de Artes (CEART), nos dias 11, 12 e 13 de setembro de 2017 que teve como temática os termos "Agouro, Ágora e Agora” para pensar as produções artístico-visuais.

${ }^{24}$ Uma revisão rápida nos editais de fomentos Municipais, Estadual e até Federal comprova esta afirmação. Mas, no caso do primeiro (Municipal de Campo Grande - Capital), o agravante é ainda maior, pois, há edital com lista de selecionados desde 2015 que não foram contemplados com os recursos e sequer têm ideias de quando isso irá ocorrer já que os mesmos foram desviados para "outros" bolsos.
} 
que circunscreve obras/sujeitos nas mesmas ideias de identidades do passado: estável e de representação de muitos por um.

Alguns artistas, nesse sentido, são importantes para "ilustrar" as discussões: por ora não quero me ater em nenhum especificamente, até para não simplesmente só ilustrar com imagens de ninguém. Mas em Mato Grosso do Sul alguns artistas que discorrem de tempos múltiplos como agoras na arte contemporânea, têm obras plásticas que situam, por exemplo, tempos contraditórios (CANTON, 2009) relativos aos que vivemos. Mais ainda agora, já que falamos das intempéries porque passam as produções em Arte. Nesse sentido, uma noção outra de plasticidade e visualidade corroborarão para melhor compreender obras, tanto plástico-visuais, tanto quanto de outras linguagens artísticas por tomar da transculturação cultural das "fronteiras" artísticas entre elas na atualidade. Logo, há outro grupo de artistas no Estado, me importa aqui aqueles que insistem em situar suas obras no passado Moderno ou Clássico a fim de galgar, agourando-os, que são aqueles que almejam os lugares canônicos da arte local para si. Vão ilustrar a esses, por exemplo, artistas e obras desses que a mais de quarenta anos insistem em reproduzir os passados, memórias e histórias da Arte local para se firmarem no presente como tais, visando ainda um lugar confortável e estável no futuro. Nesse sentido, nem sempre as obras desses artistas estão inscritas nas ideias de Arte Contemporânea ressaltadas pelos discursos do poder em Arte, mas estão apenas sendo rotuladas em arte de um tempo atual a fim de representação. Do mesmo jeito, vivendo em função do passado, esses artistas locais lidam com seus próprios tempo, espaço, memórias, histórias e sujeitos da atualidade como se fossem iguais para todos os sul-mato-grossenses.

\footnotetext{
Diante desse quadro instável, parece ser necessário explicitar, mesmo que em seus traços mais básicos, o que está em jogo nas produções recentes de vários artistas que têm buscado enfrentar, cada um à sua maneira, essa situação de descompasso entre a realidade e sua tradução no campo do sensível. Em particular, discutir o sentido último de a arte representar o mundo de maneiras distintas das legitimadas; de figurar o lugar em que se deseja viver no futuro, na medida em que esse lugar projetado é diferente do mundo existente agora. Parece ser preciso, por fim, atentar para a potência que a arte embute de não somente resistir ao que aí está e antecipar o que pode vir, mas de algum modo participar da invenção desse lugar que ainda não há. (ANJOS, 2017, p. 1)
}

Talvez fosse melhor dizer que a potência da arte sempre existiu nela, mas a grande verdade é que as teorias e críticas que lidam com essas produções é que sempre foram impotentes em relação à arte dos seus tempos. Teóricos e críticos parecem sempre estar atrasados em relação às produções artístico-culturais que emergem em seus tempos.

Por último, existem outros artistas locais que, eles próprios, estão "levando" suas produções e/ou práticas artísticas a lugares institucionais ou comerciais como se fossem as 
ágoras antigas onde o julgamento tinha valor, a fim de popularizá-las em contextos múltiplos da arte como arte que representasse o local. Indiferentemente do quão isso acaba por influenciar nas diretrizes dos seus supostos "projetos" artísticos pessoais, esses artistas lidam com coisas quase primárias em arte. Desses artistas, que até talvez se inscrevam sujeitos como artistas contemporâneos e/ou artistas da atualidade, obras e discursos sobre esses servem para situar a questão fundamental das tendências em arte: mostrar a situação precária com que são tratados os múltiplos agoras da produção artística e artistas do nosso tempo em Mato Grosso do Sul tendo em vista que o uso de tendências migrantes é muito maior que convergências de pensamentos epistêmicos outros nesse local cultural. Dos grupos de artistas aqui suscitados, alguns, na sua grande maioria, acabamos por ver que se sustentam, ou melhor, são literalmente sustentados como tais pelos discursos políticos e econômicos nos tempos dos agoras atual. Ora são inscritas/inscritos como produções/produtores que apenas (re)produzem histórias alheias, ora falam ou promovem falas a respeito de seus trabalhos, visando situação nas ágoras contemporâneas (museus, galerias institucionais, galerias comerciais ou em outros espaços avalizados pelo Estado-nação) em busca de uma suposta representação pelas suas tendências, mas quase sempre sem levar em consideração de fato onde estão as suas representações da cultura local?!.

\footnotetext{
De início, é preciso lembrar que qualquer produção artística está sempre ligada, com menor ou maior evidência ou consciência, aos lugares e aos tempos vividos por seus autores. Aquilo que é inventado pelos artistas, ou mediado por suas subjetividades, sempre deixa transparecer, como sintoma ou como análise, a situação e o contexto específicos que lhe serve de chão e calha. São criações que estabelecem e que reiteram, a cada ambiente e a cada momento, um conjunto de pistas e de vestígios que desenham maneiras singulares de estar no mundo, próprias a uma dada comunidade. É nesse sentido que se pode dizer que essas criações são equivalentes sensíveis de uma determinada realidade e se configuram, portanto, como práticas de representação. (ANJOS, 2017, p. 2)
}

Desta ótica até aqui exposta, as tendências - que são divergentes do pensamento Moderno europeu e do pensamento Pós-Moderno estadunidense - tomadas como epistêmicas a partir de sujeitos-bios, espaços-geos e as narrativas-grafias, BIOgeografias (BESSAOLIVEIRA, 2016), ou de Cultura Bugresca, nas produções artístico-visuais que obrigam-nos (des)focalizar os tradicionais conceitos, tempos, espaços, sujeitos, memórias e histórias da produção de lugares não situados na Europa ou nos Estados Unidos, fazem-nos perceber paisagens outras na arte latino-americana. Pois, essas epistemologias estão, por exemplo, cobrando dos artistas, nas obras de arte, a apresentação mais real de sujeitos, espaços e narrativas associados às nossas realidades para além daquelas tratadas por artistas e críticos Modernos e Clássicos “Ocidentais”. E do mesmo jeito estão suspeitando de que as teorias e os 
críticos ainda se valem de tendências migradas da Europa e dos Estados Unidos para relacionar, mal e porcamente, nossas produções bugras às brancas ocidentais. Esta questão teórico-crítica obriga-nos, portanto, numa discussão desta natureza, (re)verificar os fatos (im)postos pelas tendências artísticas e/ou teóricas nas/pelas também produções artísticovisuais (mas culturais) e fazer a revisão dos conceitos de memória e história e, logo, dos conceitos de obra de arte (Clássico) bem como o de estética (Moderno) que sustentam/apagam as obras artísticas até então produzidas nos locais exteriorizados porque são dessas culturas. Nesta empreitada as ideias de cronologia, continuidade e de passado histórico como únicos mecanismos para explicação do presente e previsão do futuro acabam por desmoronarem-se por entender as múltiplas histórias locais em oposição à ideia de projetos globais (europeu no século XV ou estadunidense posto no século XX).

São histórias locais e, igualmente os sujeitos, espaços e narrativas emergentes que evidenciam "Agouro, Ágora, Agora" - como quis o evento na UDESC -, nas produções artísticas aqui tratadas de uma perspectiva epistêmica outra diferente da de continuidade e/ou cronologia europeia, arte, cultura e conhecimentos da diferença. Essas histórias locais outras, foram, são e serão, se não (re)verificados o foco de "leituras e leitores" dessas obras e sujeitos, sempre vistos como continuidades daquelas histórias clássicas e/ou modernas de subordinação desses mesmos sujeitos periféricos. Do mesmo jeito, lugares fora dos centros que fazem emergir esses discursos outros nunca são produtores de arte, cultura e conhecimentos (através ou não da arte - agora sem rótulos temporais de passado, presente ou futuro) porque são desconsiderados pelos pensamentos hegemônicos de arte, cultura e conhecimentos. Dos artistas aqui aludidos, ainda que sem nominá-los, tratados a partir das suas obras quase todas pictóricas, posso dizer que se situam na ideia de reprodutores da identidade "cultural" que tomam de imagens que representam o todo (exótico) a partir de Única ideia de paisagem local da cultura de Mato Grosso do Sul - o agora sustentado pela ideia de imagens clássicas e modernas ancorados pelo discurso público. Se um faz de redes e da flora sul-mato-grossense suas pinturas, outro continua reforçando o boi (animal vasto no agronegócio por aqui) como representação fiel da sociedade $d o$ boi da fronteira sul do CentroOeste brasileiro. Desses, ambos fazem da cultura sul-mato-grossense repositório (quase como supositório nos sujeitos) das suas paisagens e bois e (re)produzem fielmente "obras" na atualidade iguais às Grandes Obras do passado.

Na verdade chego a pensar que falar de paisagem daqui, biográfica como tenho falado ou biogeográfica como tenho preferido pensar mais ultimamente, está por descrever o 
local a partir de uma perspectiva outra que não está somente assentada em uma estética moderna por excelência europeia, branca e heterossexualmente fálica como vêm sendo mostrada por alguns artistas e críticos sul-mato-grossenses. Mas está, por exemplo, posta na condição de uma paisagem que toma de uma sensibilidade da simplicidade de culturas bugrescas que as culturas brancas e letradas nunca poderão supor como é expô-las. Ou seja, essa ideia de paisagem não está para o belo, para o formal, para uma estética da tradição ou para noções de "pureza" ou de "autenticidade" que sustentam um único padrão de arte, cultura e conhecimento ancorados em pressupostos excludentes, eurocentrados e preconceituosos que assassinaram as exterioridades. Não está também para ideia de binarismos, pois, biogeografias se constituem em qualquer lugar. Por fim, a condição de nascimento na fronteira não faz do sujeito fronteiriço um epistêmico da condição da fronteira em condição pós-colonial ou da condição de quem habi(ES)tamos em condição de fronteira (teórico, crítico, artístico ou pedagogicamente falando) se este não é sensível à fronteira como lugar geoistórico epistêmico - biogeográfico! E este é o caso da nossa maior parte da crítica e de muitas produções artísticas no sentido paisagístico moderno. $\mathrm{O}$ artista e o crítico locais ainda insistem em uma ideia de paisagem natural! Mas minhas reflexões estão para a ideia de que "O autor fronteiriço desenvolveu seu pensamento fronteiriço não simplesmente por ser um sujeito oriundo da fronteira, mas por suas vivências e experiências obtidas nesse lócus particular que é a fronteira-sul" (VILELA, 2017, p. 19-20).

\section{Referências}

ACHUGAR, H. Planetas sem boca: escritos efêmeros sobre arte, cultura e literatura. Tradução de Lyslei Nascimento. Belo Horizonte: Ed. da UFMG, 2006.

ANJOS, Moacir dos. "A arte brasileira e a crise de representação". In: Revista ZUM/IMS Revista de Fotografia. São Paulo: Instituto Moreira. Publicado em: 07 de julho de 2017, p. 1-6. Disponível em: http://revistazum.com.br/colunistas/crise-de-representacao/ - acessado em: 10 de julho de 2017.

BARRETO, Adeline Silva; BESSA-OLIVEIRA, Marcos Antônio. "Pesquisa(s) em Arte(s) pensando processos investigativos na UEMS". In: BESSA-OLIVEIRA, Marcos Antônio. (Org.). NAV(r)E - Pesquisa e Produção de Conhecimento em Arte na Universidade: artista, professor, pesquisador. Campo Grande, MS: Life Editora, 2018, p. 37-48.

BESSA-OLIVEIRA, Marcos Antônio. Paisagens Biográficas Pós-Coloniais: Retratos da Cultura Local Sul-Mato-Grossense. Campo Grande, MS: Life Editora, 2018.

BESSA-OLIVEIRA, Marcos Antônio; NOLASCO, Edgar Cézar. (Orgs.). Fronteiras Culturais em Contextos Epistêmicos Descoloniais. Campo Grande, MS: Life Editora, 2018. 
BESSA-OLIVEIRA, Marcos Antônio. (Org.). NAV(r)E - Pesquisa e Produção de Conhecimento em Arte na Universidade: artista, professor, pesquisador. Campo Grande, MS: Life Editora, 2018.

BESSA-OLIVEIRA, Marcos Antônio; NOLASCO, Edgar Cézar; GUERRA, Vânia Maria Lescano; FREIRE, Zélia R. Nolasco dos S.. (Orgs.). Fronteiras Platinas em Mato Grosso do Sul (Brasil/Paraguai/Bolívia): biogeografias na arte, crítica biográfica fronteiriça, discurso indígena e literatura de fronteira. Campinas, SP: Pontes Editores, 2017.

BESSA-OLIVEIRA, Marcos Antônio. "Estética (ou não) Bugresca - Arte descolonial fronteiriça - paisagens biogeográficas: o que vemos do outro lado da linha que se insinua entre o real e o imaginário". In: Cadernos de Estudos Culturais: Estéticas Periféricas. V. 8. N. 16. Campo Grande, MS: Ed. UFMS, ago.-dez., 2016, p. 209-222.

"BIOgeografias Ocidentais/Orientais: (i)migrações do bios e das epistemologias artísticas no front". In: Cadernos de Estudos Culturais: Ocidente/Oriente: migrações. v. 8. n. 15. Campo Grande, MS: Ed. UFMS, jan.-jun., 2016, p. 97-144.

BHABHA, Homi K.. O local da cultural. Tradução Myriam Ávila, Eliana Lourenço de Lima Reis, Gláucia Renate Gonçalves. Belo Horizonte: Ed. UFMG, 1998.

CANTON, Katia. Narrativas enviesadas. São Paulo: Editora WMF Martins Fontes, 2009. [Coleção temas da arte contemporânea].

GÓMEZ MORENO, Pedro Pablo; MIGNOLO, Walter. Estéticas decoloniales [recurso electrónico]/Pedro Pablo Gómez, Walter Mignolo.- Bogotá: Universidad Distrital Francisco José de Caldas, 2012.

HALL, Stuart. Cultura e representação. Organização e revisão técnica: Arthur Ituassu; Tradução: Daniel Miranda e William Oliveira. Rio de Janeiro: Ed. PUC-Rio: Apicuri, 2016.

HALL, Stuart. Da diáspora: identidades e mediações culturais. Organização Liv Sovik; Tradução Adelaina La Guardia Resende ... [et al]. Belo Horizonte: Editora UFMG; Brasília: Representação da UNESCO no Brasil, 2003. (Humanitas)

HISSA, Cássio E. Viana. (Org.). Conversações: de artes e de ciências. Belo Horizonte: Editora UFMG, 2011. (Humanitas).

MIGNOLO, Walter D.; GÓMEZ, Pedro Pablo. Trayectorias de re-existencia: ensayos en torno a la colonialidad/decolonialidad del saber, el sentir y el creer. Bogotá: Universidad Distrital Francisco José de Caldas, 2015.

MIGNOLO, Walter. D.. "Prefacio". In: ZULMA, Palermo. Para una pedagogia decolonial. $1^{\mathrm{a}}$ ed.. Ciudad Autónoma de Buenos Aires: Del Signo, 2014, p. 7-13. (El desprendimento / Walter Mignolo. MIGNOLO, Walter D..)

MIGNOLO, Walter. "Prefácio". In: PALERMO, Zulma. (Comp.). Arte y estética em la encrucijada descolonial. $1^{\text {a }}$ ed.. Buenos Aires: Del signo, 2009, p. 7-14. 
MIGNOLO, Walter D.. "Desobediência epistêmica: a opção descolonial e o significado de identidade em política". In: Cadernos de Letras da UFF - Dossiê: Literatura, língua e identidade, $\mathrm{n}^{\circ}$. 34, p. 287-324, 2008. Disponível em: http://www.uff.br/cadernosdeletrasuff/34/traducao.pdf - acessado em: 22 de junho de 2018.

MIGNOLO, Walter D.. Histórias locais / Projetos globais: colonialidade, saberes subalternos e pensamento liminar. Trad. Solange Ribeiro de Oliveira. Belo Horizonte: Editora UFMG, 2003. (Humanitas).

MOREIRA, Antonio Flávio; CANDAU, Vera Maria. (Orgs.). Multiculturalismo: diferenças culturais e práticas pedagógicas. 10. ed.. Petrópolis, RJ: Vozes, 2013.

PALERMO, Zulma. "Introducción - El arte latinoamericano em la encrucijada decolonial". In: PALERMO, Zulma. (Comp.). Arte y estética em la encrucijada descolonial. $1^{\mathrm{a}}$ ed.. Buenos Aires: Del signo, 2009, p. 15-26.

SANTIAGO, Silviano. Uma Literatura nos Trópicos. 2 ed. Rio de Janeiro: Rocco, 2000.

VILELA, Adrielly Ferreira. Entre fronteiras e balaios: a literatura bugresca de Hélio Serejo. Dissertação de Mestrado defendida no Programa de Pós-Graduação Mestrado em Estudos de Linguagens, agosto de 2017. 